\title{
Skin autofluorescence, a non-invasive biomarker for advanced glycation end products, is associated with the metabolic syndrome and its individual components
}

Robert P. van Waateringe ${ }^{1 *}$, Sandra N. Slagter ${ }^{1}$, Andre P. van Beek , Melanie M. van der Klauw', Jana V. van Vliet-Ostaptchouk', Reindert Graaff', Andrew D. Paterson², Helen L. Lutgers ${ }^{3}$

and Bruce H. R. Wolffenbuttel ${ }^{1}$

\begin{abstract}
Background: The metabolic syndrome (MetS) comprises several cardiometabolic risk factors associated with increased risk for both type 2 diabetes and cardiovascular disease. Skin autofluorescence (SAF), a non-invasive biomarker of advanced glycation end products accumulation, is associated with cardiovascular complications in subjects with diabetes. The aim of the present study was to examine the association between SAF and the presence of MetS as well as its individual components in a general population.

Methods: For this cross-sectional analysis, we included 78,671 non-diabetic subjects between 18 and 80 years of age who participated in the LifeLines Cohort Study and had SAF measurement obtained non-invasively using the AGE Reader. MetS was defined according to the revised NCEP ATP III criteria. Students unpaired $t$ test was used to test differences between groups. Both logistic and linear regression analyses were performed in order to test associations between the individual MetS components and SAF.

Results: Subjects with MetS had higher SAF (2.07 \pm 0.45 arbitrary units, AU) compared to individuals without MetS $(1.89 \pm 0.42 \mathrm{AU})(p<0.001)$. There was a positive association between the number of MetS components and higher SAF Z-scores ( $p<0.001)$. Individuals in the highest SAF tertile had a higher presence of MetS (OR 2.61; $95 \% \mathrm{Cl}$ 2.48-2.75) and some of the individual components compared to subjects in the lowest SAF tertile. After correction for age, gender, creatinine clearance, HbA1c and smoking status, only elevated blood pressure and low HDL cholesterol remained significantly associated with higher $\operatorname{SAF}(p=0.002$ and $p=0.001$ respectively).

Conclusion: Skin autofluorescence was associated with the presence of MetS and some of its individual components. In addition, increasing SAF Z-scores were observed with a higher number of MetS components. Prospective studies are needed to establish whether SAF can be used as an (additional) screening tool to predict both cardiovascular disease and type 2 diabetes in high-risk populations.
\end{abstract}

\section{Background}

Advanced glycation end products (AGEs) comprise a group of largely irreversibly glycated proteins, lipids and

\footnotetext{
*Correspondence: r.p.van.waateringe@umcg.nl

1 Department of Endocrinology, University of Groningen, University

Medical Center Groningen, HPC AA31, P.O. Box 30001, 9700 RB Groningen,

The Netherlands

Full list of author information is available at the end of the article
}

nucleic acids which represent chronic exposure to hyperglycaemia and oxidative stress $[1,2]$. AGEs are formed via several pathways, usually the Maillard reaction between carbonyl groups of reducing sugars and free amino groups from proteins. AGEs accumulate in the skin as a result of ageing $[3,4]$. The formation and accumulation may be increased as a result of both endogenous and exogenous factors, including hyperglycaemia in diabetes, 
impaired renal excretion in subjects with kidney failure, as well as dietary intake and tobacco smoking [5-8].

Since the past decade, it has become possible to estimate tissue AGE accumulation non-invasively by measuring autofluorescence of the skin (SAF) [9]. In our previous study we showed that SAF was associated with several clinical and lifestyle parameters [10]. SAF has previously been validated against tissue AGE measurements and reference values against age were obtained $[11,12]$. SAF was reported to be elevated in subjects with type 1 and 2 diabetes $[9,13]$. Moreover, SAF has been shown to be a strong predictor of long-term cardiovascular complications and mortality in both type 1 and type 2 diabetes and end-stage renal failure [14-18]. In addition, recent studies have shown higher SAF levels to be associated with coronary artery disease, peripheral artery disease and (sub)clinical atherosclerosis independent of diabetes [19-21].

The metabolic syndrome (MetS) is a cluster of cardiometabolic abnormalities associated with increased risk for cardiovascular disease (CVD) and type 2 diabetes mellitus [22,23]. The MetS is a worldwide problem which prevalence increases worldwide, particularly due to the growing epidemic of obesity [24-26]. Glycation is known to play an essential role in the mechanism that leads to the formation of AGEs [6].

It has been shown that AGEs increase inflammation and oxidative stress hereby promoting insulin resistance. On the other hand, a low AGEs diet improves insulin sensitivity $[27,28]$.

However, the association of the other cardiometabolic components with SAF has not been assessed in detail. As SAF measurement might be used as a future screening tool in high-risk populations, such as the MetS, to refine estimation of risk of future cardiovascular events or development of type 2 diabetes, knowledge of potential associations with SAF is important. Therefore, the aim of this cross-sectional study was to assess SAF in subjects with MetS. We examined the association between the individual MetS components and SAF in a large-scale general population.

\section{Methods}

\section{Participants}

Subjects included were participants from the LifeLines Cohort Study [29], a large population-based cohort study in the northern region of the Netherlands examining the interaction between genetic and environmental factors associated with chronic diseases and healthy ageing. Between 2006 and 2013, individuals from the three northern provinces of the Netherlands were invited to participate in the study. At baseline, both physical examination and extensive questionnaires were collected from more than 167,000 participants [30]. All participants have provided written informed consent before participating in the study. The study has been approved by the Medical Ethics Review Committee of the University Medical Center Groningen. For the present study, we included subjects of Western European descent between 18 and 80 years of age having a SAF measurement available $(\mathrm{n}=82,515)$. We excluded subjects with either missing data for MetS status $(\mathrm{n}=1221)$ and those with a serum creatinine $>140 \mu \mathrm{mol} / \mathrm{L}(\mathrm{n}=75)$, as severely reduced kidney function itself increases AGE levels. Furthermore, subjects with missing data for diabetes status $(n=86)$ were excluded, as were those with type 1 diabetes $(n=177)$, type 2 diabetes $(n=2157)$ or previous gestational diabetes $(\mathrm{n}=128)$ leaving 78,671 non-diabetic individuals for analyses.

\section{Clinical and lifestyle data}

The following clinical data were used: age, gender, body mass index (BMI), waist circumference, systolic and diastolic blood pressure, serum lipids, fasting plasma glucose, HbA1c, creatinine clearance, use of medication, and selfreported history of CVD (myocardial infarction and cerebrovascular accident). Information regarding smoking behaviour was collected by extensive questionnaires, as described earlier [10]. Pack-years of smoking were calculated as the number of cigarette packages smoked per day multiplied by the number of years an individual had smoked. Data regarding coffee consumption (cups of coffee per day) were obtained by questionnaire. We were not able to distinguish between caffeinated and decaffeinated coffee consumption.

\section{Physical measurements}

Weight was measured to the nearest $0.1 \mathrm{~kg}$ and height and waist circumference to the nearest $0.5 \mathrm{~cm}$ by trained technicians using calibrated measuring equipment, with participants wearing light clothing and no shoes. Waist circumference was measured with a tape around the body between the lower rib margin and the iliac crest. BMI was calculated as weight divided by height squared $\left(\mathrm{kg} / \mathrm{m}^{2}\right)$. Systolic and diastolic blood pressure were measured every minute during $10 \mathrm{~min}$ in the supine position using an automated Dinamap Monitor (GE Healthcare, Freiburg, Germany). The average of the last three readings was recorded. SAF was assessed as the mean of three consecutive measurements using the AGE Reader (DiagnOptics Technologies BV, Groningen, the Netherlands) in all participants, as described previously [9-11]. 


\section{Biochemical measures}

Blood samples were taken in the fasting state between 8.00 and 10.00 a.m. and transported to the LifeLines laboratory facility at room temperature or at $4{ }^{\circ} \mathrm{C}$, depending on the sample requirements. On the day of collection, HbA1c (EDTA-anticoagulated) was analyzed using a NGSP-certified turbidimetric inhibition immunoassay on a Cobas Integra 800 CTS analyzer (Roche Diagnostics Nederland BV, Almere, the Netherlands). Serum creatinine was measured on a Roche Modular P chemistry analyzer (Roche, Basel Switzerland), and creatinine clearance was calculated with the chronic kidney disease epidemiology collaboration (CKD-EPI) formula [31]. Total and high density lipoprotein (HDL) cholesterol were measured using an enzymatic colorimetric method, triglycerides using a colorimetric UV method, and low density lipoprotein (LDL) cholesterol using an enzymatic method, on a Roche Modular P chemistry analyzer (Roche, Basel, Switzerland). Fasting blood glucose was measured using a hexokinase method.

\section{Definition of the metabolic syndrome}

Diagnosis of MetS was established if a subject satisfied at least three out of five criteria according to the revised National Cholesterol Education Programs Adults Treatment Panel III (NCEP ATPIII criteria) [22]: (1) systolic blood pressure $\geq 130 \mathrm{mmHg}$ and/or diastolic blood pressure $\geq 85 \mathrm{mmHg}$ and/or use of antihypertensive medication; (2) HDL cholesterol levels $<1.03 \mathrm{mmol} / \mathrm{L}$ in men and $<1.30 \mathrm{mmol} / \mathrm{L}$ in women and/or use of lipid-lowering medication influencing HDL levels; (3) triglyceride levels $\geq 1.70 \mathrm{mmol} / \mathrm{L}$ and/or use of triglyceride-lowering medication; (4) waist circumference $\geq 102 \mathrm{~cm}$ in men and $\geq 88 \mathrm{~cm}$ in women; (5) fasting glucose level between 5.6 and $7.0 \mathrm{mmol} / \mathrm{L}$. As mentioned earlier, people with diabetes were excluded from analysis to reflect 'true' MetS.

\section{Calculations and statistical analyses}

Data are shown as mean \pm standard deviation (SD) or median and interquartile range (IQR) in case of nonnormally distributed data. Student's unpaired $t$ test, Analysis of Variance (ANOVA) or Chi Square test were performed to compare groups. Age-adjusted SAF levels (Z-scores) were calculated based on the total population (separated for males and females) as SAF and MetS are strongly affect by ageing $[10,32]$. Next, we classified individuals into tertiles of their age-adjusted SAF Z-scores, in men: lowest SAF $Z \leq-0.59$, intermediate $\mathrm{SAF}-0.60<\mathrm{Z}<0.49$ and highest $\mathrm{SAF} Z \geq 0.50$; in women: lowest SAF $Z \leq-0.72$, intermediate SAF $-0.73<\mathrm{Z}<0.33$ and highest SAF $\mathrm{Z} \geq 0.34$. Logistic regression analysis was performed to assess whether either of the SAF groups (low SAF was set as a reference) were associated with the presence of MetS and its components. Model 1 shows the unadjusted association between tertiles of SAF Z-scores and MetS as well as its individual components. In model 2 , we adjusted for gender and BMI. In model 3, we additionally adjusted for creatinine clearance, HbA1c, current smoking, pack-years and CVD history. Linear regression analysis was performed to examine the association between each of the individual MetS components and SAF among the population with MetS. In the multivariate models, we adjusted for determinants of SAF reported in our previous study, including age, gender, BMI, creatinine clearance, HbA1c, smoking status, packyears, and CVD history [10]. SPSS (version 22, IBM, Armonk, NY, USA) was used for statistical analyses. A $p$ value $<0.001$ (two-tailed) was considered statistically significant.

\section{Results}

\section{Clinical characteristics}

Table 1 shows the clinical characteristics of the study population stratified for gender and MetS status. The overall prevalence of MetS was 19\% in men and 12\% in women.

In both genders, individuals with MetS were older than subjects without MetS and had a significantly higher BMI and waist circumference (all p $<0.001$ ). Both in men and women, the prevalence of MI $(3.5 \%$ in men and $1.0 \%$ in women) and CVA (1.1\% in men and $1.2 \%$ in women) was higher among individuals with MetS compared to subjects without MetS $(\mathrm{p}<0.001)$. The percentage of current smokers as well as the number of pack-years smoked ( $\mathrm{p}<0.001)$ were higher in the participants with MetS. In addition, both men and women with MetS reported higher consumption of coffee compared to individuals without MetS ( $\mathrm{p}<0.001)$. Mean SAF levels were significantly higher among both male and female subjects with MetS compared to individuals without MetS (men: $2.07 \pm 0.44 \mathrm{AU}$ vs $1.94 \pm 0.43 \mathrm{AU}, \mathrm{p}<0.001$; women: $2.07 \pm 0.45 \mathrm{AU}$ vs $1.86 \pm 0.42 \mathrm{AU}, \mathrm{p}<0.001)$. In subjects with MetS, mean SAF levels were not different between men and women $(2.07 \pm 0.44 \mathrm{AU}$ vs $2.07 \pm 0.45 \mathrm{AU}$, $\mathrm{p}=0.715)$. However, among individuals without MetS, men had significantly higher SAF levels than women $(1.94 \pm 0.43 \mathrm{AU}$ vs $1.86 \pm 0.42 \mathrm{AU}, \mathrm{p}<0.001)$ (data not shown). Furthermore, mean SAF was $2.33 \pm 0.50 \mathrm{AU}$ in subjects with a history of $\mathrm{MI}$ and $1.91 \pm 0.43 \mathrm{AU}$ in subjects without a history of MI $(\mathrm{p}<0.001)$. Mean SAF was $2.22 \pm 0.50 \mathrm{AU}$ in subjects with a history of CVA and $1.91 \pm 0.43 \mathrm{AU}$ in subjects without a history of CVA $(\mathrm{p}<0.001)$ (data not shown). Finally, within obese individuals, subjects with MetS had a higher SAF than individuals without MetS $(2.11 \pm 0.47 \mathrm{AU}$ vs $1.94 \mathrm{v} 0.41 \mathrm{AU}$, 
Table 1 Clinical characteristics of the study population stratified by MetS status and gender

\begin{tabular}{|c|c|c|c|c|}
\hline \multirow[t]{2}{*}{ Characteristic } & \multicolumn{2}{|l|}{ Men $(n=32,601)$} & \multicolumn{2}{|c|}{ Women $(n=46,070)$} \\
\hline & MetS & Without MetS & MetS & Without MetS \\
\hline n (\%) & $6220(19)$ & $26,381(81)$ & $5367(12)$ & $40,703(88)$ \\
\hline Age (years) & $49 \pm 11^{*}$ & $44 \pm 13$ & $50 \pm 12^{*}$ & $44 \pm 12$ \\
\hline Body mass index $\left(\mathrm{kg} / \mathrm{m}^{2}\right)$ & $29.8 \pm 3.6^{*}$ & $25.5 \pm 3.1$ & $30.6 \pm 5.1^{*}$ & $25.1 \pm 4.1$ \\
\hline Waist circumference (cm) & $106 \pm 9^{*}$ & $93 \pm 9$ & $100 \pm 11^{*}$ & $85 \pm 11$ \\
\hline Systolic blood pressure $(\mathrm{mmHg})$ & $141 \pm 14^{*}$ & $129 \pm 14$ & $138 \pm 16^{*}$ & $121 \pm 15$ \\
\hline Diastolic blood pressure $(\mathrm{mmHg})$ & $82 \pm 9^{*}$ & $76 \pm 9$ & $79 \pm 9^{*}$ & $72 \pm 9$ \\
\hline Total cholesterol (mmol/L) & $5.4 \pm 1.1^{*}$ & $5.1 \pm 1.0$ & $5.4 \pm 1.1^{*}$ & $5.0 \pm 1.0$ \\
\hline HDL cholesterol (mmol/L) & $1.04 \pm 0.23^{*}$ & $1.37 \pm 0.30$ & $1.24 \pm 0.30^{*}$ & $1.65 \pm 0.38$ \\
\hline LDL cholesterol (mmol/L) & $3.56 \pm 0.93^{*}$ & $3.35 \pm 0.89$ & $3.57 \pm 0.95^{*}$ & $3.05 \pm 0.88$ \\
\hline Triglycerides (mmol/L) & $2.03(1.60-2.73)^{*}$ & $1.04(0.77-1.40)$ & $1.72(1.18-2.14)^{*}$ & $0.83(0.64-1.11)$ \\
\hline Creatinine clearance $(\mathrm{mL} / \mathrm{min})^{\mathrm{a}}$ & $137 \pm 36^{*}$ & $124 \pm 28$ & $125 \pm 39^{*}$ & $111 \pm 29$ \\
\hline Creatinine clearance $(\mathrm{mL} / \mathrm{min})^{\mathrm{b}}$ & $130 \pm 18^{*}$ & $128 \pm 16$ & $135 \pm 21$ & $134 \pm 18$ \\
\hline Fasting plasma glucose (mmol/L) & $5.45 \pm 0.55^{*}$ & $4.98 \pm 0.43$ & $5.33 \pm 0.61^{*}$ & $4.75 \pm 0.42$ \\
\hline HbA1c (\%) & $5.7 \pm 0.3^{*}$ & $5.5 \pm 0.3$ & $5.7 \pm 0.4^{*}$ & $5.5 \pm 0.3$ \\
\hline $\mathrm{HbA} 1 \mathrm{c}(\mathrm{mmol} / \mathrm{mol})$ & $38.5 \pm 3.8$ & $36.7 \pm 3.2$ & $39.3 \pm 3.9$ & $36.5 \pm 3.2$ \\
\hline Statin use, n (\%) & $783(13)^{*}$ & $1260(5)$ & $554(10)^{*}$ & $1029(3)$ \\
\hline TG-lowering medication, n (\%) & $44(1)^{*}$ & $9(0.01)$ & $16(0.3)^{*}$ & $3(0.01)$ \\
\hline BP-lowering medication, $\mathrm{n}(\%)$ & $1445(23)^{*}$ & $2008(8)$ & $1919(36)^{*}$ & $3099(8)$ \\
\hline $\mathrm{Ml}, \mathrm{n}(\%)$ & $214(3.5)^{*}$ & $289(1.1)$ & $56(1.0)^{*}$ & $94(0.2)$ \\
\hline CVA, n (\%) & $70(1.1)^{*}$ & $188(0.7)$ & $66(1.2)^{*}$ & $203(0.5)$ \\
\hline Coffee consumption (cups per day) & $4.7(2.8-5.6)^{*}$ & $3.7(2.8-5.6)$ & $3.3(1.9-4.7)^{*}$ & $2.8(1.3-4.7)$ \\
\hline \multicolumn{5}{|l|}{ Smoking status, n (\%) } \\
\hline Non-smokers & $2117(34)^{*}$ & $12,259(47)$ & $2203(41)^{*}$ & $19,836(49)$ \\
\hline Ex-smokers & $2425(39)$ & $8271(32)$ & $1899(36)$ & $12,847(32)$ \\
\hline Current smokers & $1629(27)$ & $5677(21)$ & $1228(23)$ & $7698(19)$ \\
\hline \multicolumn{5}{|l|}{ Pack-years } \\
\hline Ex-smokers & $12.8(6.5-21.9)^{*}$ & $8.2(3.8-15.0)$ & $7.8(3.5-15.3)^{*}$ & $5.2(2.2-10.4)$ \\
\hline Current-smokers & $18.0(10.7-27.0)^{*}$ & $12.9(6.4-21.5)$ & $16.9(9.6-26.3)^{*}$ & $11.2(5.4-18.8)$ \\
\hline SAF (AU) & $2.07 \pm 0.44^{*}$ & $1.94 \pm 0.43$ & $2.07 \pm 0.45^{*}$ & $1.86 \pm 0.42$ \\
\hline SAF Z-score & $0.21 \pm 0.02^{*}$ & $0.04 \pm 0.01$ & $0.19 \pm 0.02^{*}$ & $-0.10 \pm 0.01$ \\
\hline
\end{tabular}

Data are presented as mean \pm standard deviation, or median (interquartile range) and number (\%)

$A U$ arbitrary units, BP blood pressure, CVA cerebrovascular accident, GFR Glomerular Filtration Rate, HDL high density lipoprotein, LDL low density lipoprotein, MetS metabolic syndrome, Mi myocardial infarction, SAF skin autofluorescence, TG triglycerides

* $p$ value $<0.001$

${ }^{a}$ Creatinine clearance (Cockcroft-Gault formula), ${ }^{\text {b }}$ Creatinine clearance (CKD EPI)

$\mathrm{p}<0.001)$. However, within the population with MetS, there was no significant difference in SAF between obese and non-obese individuals $(2.07 \pm 0.45 \mathrm{AU}$ vs $2.06 \mathrm{v} 0.45$ $\mathrm{AU}, \mathrm{p}=0.46)$ (data not shown).

\section{The association between SAF and the number of MetS components}

In both men and women, we observed a gradual rise in age-adjusted SAF Z-scores with higher number of individuals MetS components. Compared to men without any MetS components, SAF Z-scores were significantly higher among subjects with $\geq 1$ MetS component $(\mathrm{p}<0.001)$. Men with $\geq 2$ MetS components had significantly higher SAF Z-scores compared to men having only one MetS component $(\mathrm{p}<0.001)$. No significant differences in SAF Z-scores were observed between men with two vs three MetS components as well as men with four vs five MetS components. Among women, SAF Z-scores were significantly higher among those with $\geq 1$ MetS component compared to women without any MetS components $(\mathrm{p}<0.001)$. Women with three, four or five MetS components had significantly higher SAF Z-scores 
compared to women with only one MetS component $(\mathrm{p}<0.001)$. No differences in SAF Z-scores were found for women with two vs one MetS components as well as three vs two MetS components. Furthermore, women with either four or five MetS components had significantly higher SAF Z-scores than women with two MetS components or three MetS components ( $\mathrm{p}<0.001)$. In men, SAF Z-scores tended to be higher in those with one, two and three MetS components while in women SAF
Z-scores were higher in three, four or five MetS components compared to men (Fig. 1).

\section{SAF and the prevalence of the individual MetS components}

Figure 2 shows the prevalence of the individual MetS components for both men and women in the total study population according to tertiles of age-adjusted SAF Z-scores. Among men, individuals in the highest SAF

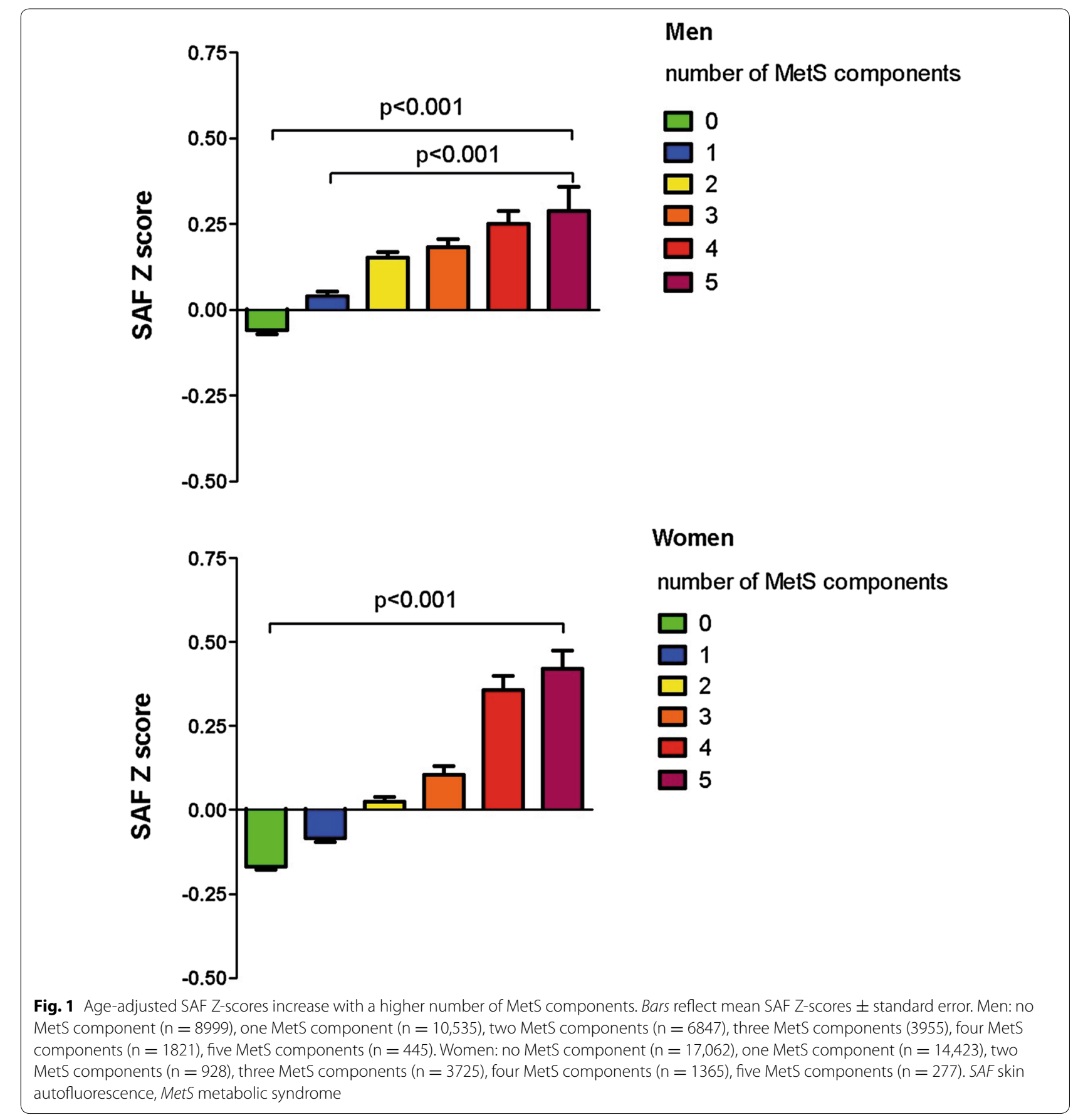




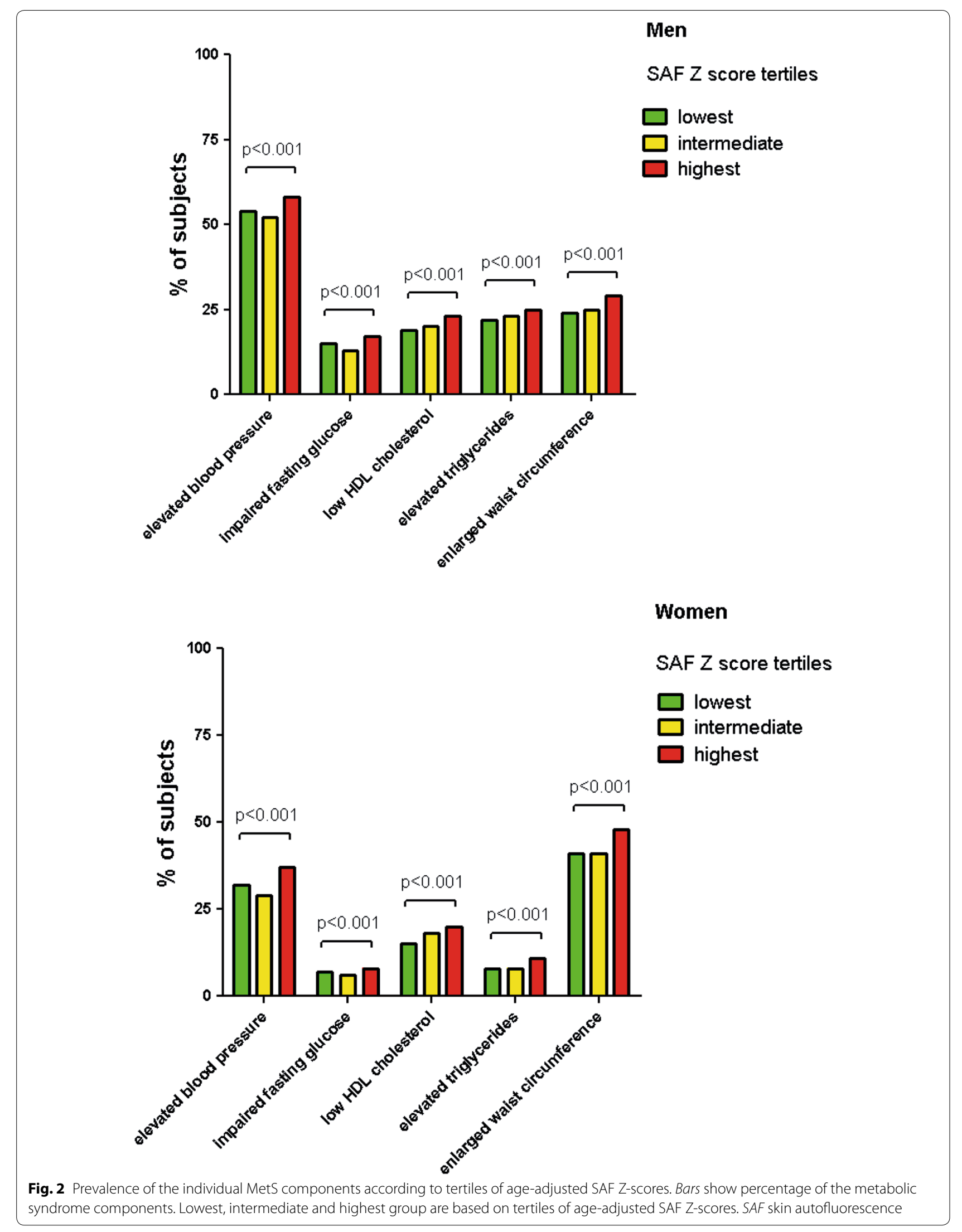


groups had a higher prevalence of elevated blood pressure $(58 \%)$ compared to subjects in the middle (52\%) and lowest SAF group (54\%).

We observed the same trend for enlarged waist circumference, impaired fasting glucose, elevated triglycerides and low HDL cholesterol (all p < 0.001).

In contrast to men, the most frequent MetS component in women was enlarged waist circumference (high SAF $48 \%$, intermediate SAF $41 \%$ and lowest SAF $41 \%$ ). There was a clear and significant trend among women within the highest SAF group, to be associated with higher prevalence of blood pressure, elevated triglycerides, lower HDL cholesterol levels and impaired fasting glucose (all $\mathrm{p}<0.001$ ).
Logistic regression analysis for the presence of MetS and it components across SAF tertiles

Table 2 shows the results of the logistic regression analyses describing the association between SAF tertiles and the presence of MetS in the total population. Compared to the low SAF group which was set as a reference, high SAF was significantly associated with a higher presence of MetS (odds ratio (OR) 2.61; 95\% CI 2.48-2.75). After adjusting for age, gender, BMI, creatinine clearance, HbA1c, smoking status, packyears, CVD history, high SAF (OR 1.24; 95\% CI 1.13-1.37) and intermediate SAF (OR 1.11; 95\% CI 1.01-1.22) remained significantly associated with the presence of MetS (Table 2, model 3).

Table 2 Unadjusted and adjusted odds ratios for metabolic syndrome and its components associated with tertiles of SAF (total population)

\begin{tabular}{|c|c|c|c|c|c|c|}
\hline \multirow[t]{2}{*}{ Metabolic syndrome } & \multicolumn{2}{|l|}{ Model 1} & \multicolumn{2}{|l|}{ Model 2} & \multicolumn{2}{|l|}{ Model 3} \\
\hline & OR & $p$ value & OR & $p$ value & OR & p value \\
\hline SAF (continuous) & $2.37(2.27-2.48)$ & $<0.0001$ & $1.36(1.28-1.44)$ & $<0.0001$ & $1.17(1.08-1.26)$ & $<0.0001$ \\
\hline Low SAF & Ref. & & Ref. & & Ref. & \\
\hline Intermediate SAF & $1.71(1.62-1.81)$ & $<0.0001$ & $1.13(1.06-1.21)$ & $<0.0001$ & $1.11(1.01-1.22)$ & 0.031 \\
\hline High SAF & $2.61(2.48-2.75)$ & $<0.0001$ & $1.38(1.29-1.48)$ & $<0.0001$ & $1.24(1.13-1.37)$ & $<0.0001$ \\
\hline \multicolumn{7}{|l|}{ Elevated blood pressure } \\
\hline SAF (continuous) & $3.03(2.92-3.14)$ & $<0.0001$ & $1.25(1.20-1.31)$ & $<0.0001$ & $1.21(1.14-1.29)$ & $<0.0001$ \\
\hline Low SAF & Ref. & & Ref. & & Ref. & \\
\hline Intermediate SAF & $1.71(1.65-1.77)$ & $<0.0001$ & $1.06(1.02-1.11)$ & 0.005 & $1.04(0.98-1.11)$ & 0.220 \\
\hline High SAF & $2.93(2.82-3.03)$ & $<0.0001$ & $1.18(1.12-1.24)$ & $<0.0001$ & $1.16(1.08-1.24)$ & $<0.0001$ \\
\hline \multicolumn{7}{|l|}{ Impaired fasting glucose } \\
\hline SAF (continuous) & $2.59(2.47-2.72)$ & $<0.0001$ & $1.17(1.10-1.25)$ & $<0.0001$ & 1.09 (1.00-1.19) & 0.049 \\
\hline Low SAF & Ref. & & Ref. & & Ref. & \\
\hline Intermediate SAF & $1.90(1.78-2.03)$ & $<0.0001$ & $1.09(1.01-1.17)$ & 0.026 & $1.08(0.97-1.20)$ & 0.185 \\
\hline High SAF & $3.16(2.97-3.37)$ & $<0.0001$ & $1.34(1.24-1.45)$ & $<0.0001$ & $1.27(1.14-1.42)$ & $<0.0001$ \\
\hline \multicolumn{7}{|l|}{ Low HDL cholesterol } \\
\hline SAF (continuous) & $1.08(1.03-1.12)$ & 0.001 & $1.46(1.39-1.54)$ & $<0.0001$ & $1.27(1.19-1.36)$ & $<0.0001$ \\
\hline Low SAF & Ref. & & Ref. & & Ref. & \\
\hline Intermediate SAF & $0.96(0.92-1.01)$ & 0.082 & $1.08(1.02-1.13)$ & 0.004 & $1.02(0.94-1.10)$ & 0.663 \\
\hline High SAF & $1.01(0.96-1.05)$ & 0.786 & $1.27(1.20-1.34)$ & $<0.0001$ & $1.13(1.04-1.22)$ & 0.003 \\
\hline \multicolumn{7}{|l|}{ Elevated triglycerides } \\
\hline SAF (continuous) & $1.78(1.70-1.85)$ & $<0.0001$ & $1.29(1.22-1.37)$ & $<0.0001$ & $1.08(1.00-1.16)$ & 0.029 \\
\hline Low SAF & Ref. & & Ref. & & Ref. & \\
\hline Intermediate SAF & $1.49(1.41-1.57)$ & $<0.0001$ & $1.12(1.05-1.18)$ & $<0.0001$ & $1.04(0.95-1.13)$ & 0.426 \\
\hline High SAF & $1.89(1.80-1.98)$ & $<0.0001$ & $1.34(1.25-1.42)$ & $<0.0001$ & $1.17(1.07-1.28)$ & 0.001 \\
\hline \multicolumn{7}{|c|}{ Enlarged waist circumference } \\
\hline SAF (continuous) & $1.89(1.82-1.95)$ & $<0.0001$ & $1.31(1.23-1.39)$ & $<0.0001$ & $1.32(1.21-1.44)$ & $<0.0001$ \\
\hline Low SAF & Ref. & & Ref. & & Ref. & \\
\hline Intermediate SAF & $1.45(1.40-1.50)$ & $<0.0001$ & $1.11(1.05-1.18)$ & 0.001 & $1.14(1.04-1.25)$ & 0.004 \\
\hline High SAF & $1.93(1.86-2.00)$ & $<0.0001$ & $1.26(1.18-1.35)$ & $<0.0001$ & $1.32(1.20-1.46)$ & $<0.0001$ \\
\hline
\end{tabular}

Data are presented as odds ratios (95\% confidence interval) per arbitrary unit (AU). SAF groups were based on tertiles of age-adjusted SAF Z-scores. Model 1 = unadjusted; model 2 = adjusted for age, gender, BMl; model 3 = adjusted for age, gender, BMI, HbA1c, creatinine clearance, current smoking, pack-years, MI and CVA

Significant associations are shown in italic

$B M I$ body mass index, CVA cerebrovascular accident, $H D L$ high density lipoprotein, $M I$ myocardial infarction, $O R$ odds ratio, $S A F$ skin autofluorescence 
Considering the individual MetS components, high SAF (OR 3.16; 95\% CI 2.97-3.37 and intermediate SAF (OR 1.90; 95\% CI 1.78-2.03) were significantly associated with the presence of impaired fasting glucose, although the OR attenuated after adjusting for several covariables (Table 2, models 1, 2 and 3). We also found high SAF (OR 2.93; 95\% CI 2.82-3.03) and intermediate SAF (OR 1.71; 95\% CI 1.65-1.77) to be associated with the presence of elevated blood pressure (Table 2, model 1). Finally, high SAF (OR 1.93; 95\% CI 1.86-2.00) and intermediate SAF (OR 1.45; 95\% CI 1.40-1.50) were also associated with the presence of enlarged waist circumference, which remained significant after adjusting for covariables (Table 2, models 1, 2 and 3).

\section{Associations for SAF in the metabolic syndrome population}

The univariate associations between the individual MetS components and SAF levels in the MetS population are shown in Table 3. In subjects with MetS, the impaired

Table 3 Associations for skin autofluorescence in the metabolic syndrome population

\begin{tabular}{|c|c|c|c|}
\hline & Coefficient B & SE & $p$ value \\
\hline \multicolumn{4}{|l|}{ Univariate model } \\
\hline Elevated blood pressure & 0.113 & 0.012 & $<0.0001$ \\
\hline Low HDL cholesterol & -0.094 & 0.009 & $<0.001$ \\
\hline Elevated triglycerides & 0.029 & 0.009 & 0.001 \\
\hline Impaired fasting glucose & 0.124 & 0.008 & $<0.0001$ \\
\hline Enlarged waist circumference & 0.038 & 0.011 & 0.001 \\
\hline \multicolumn{4}{|l|}{ Multivariate model } \\
\hline Elevated blood pressure & 0.044 & 0.015 & 0.003 \\
\hline Low HDL cholesterol & 0.036 & 0.012 & 0.002 \\
\hline Elevated triglycerides & -0.001 & 0.011 & 0.920 \\
\hline Impaired fasting glucose & 0.008 & 0.012 & 0.502 \\
\hline Enlarged waist circumference & 0.016 & 0.014 & 0.269 \\
\hline Age & 0.019 & 0.001 & $1.3 \times 10^{-159}$ \\
\hline Male gender & -0.016 & 0.011 & 0.272 \\
\hline Creatinine clearance (mL/min) & 0.001 & 0.0002 & 0.014 \\
\hline $\mathrm{HbA} 1 \mathrm{c}(\%)$ & 0.055 & 0.016 & $2.3 \times 10^{-4}$ \\
\hline $\begin{array}{l}\text { Coffee consumption (cups/ } \\
\text { day) }\end{array}$ & 0.024 & 0.002 & $6.6 \times 10^{-29}$ \\
\hline Current smoking $^{\mathrm{a}}$ & 0.116 & 0.011 & $1.1 \times 10^{-23}$ \\
\hline Pack-years & 0.004 & 0.0003 & $5.6 \times 10^{-31}$ \\
\hline $\mathrm{Ml}$ & 0.062 & 0.029 & 0.033 \\
\hline CVA & 0.026 & 0.043 & 0.562 \\
\hline
\end{tabular}

Data are shown as coefficient $B$ (standard error) per arbitrary unit (AU). The individual MetS components were included into the model as categorical variables (yes/no) while the other variables were continuous variables Significant associations are shown in italic

CVA cerebrovascular accident, $H D L$ high density lipoprotein, $M I$ myocardial infarction

a Current smoking vs non- and former smoking fasting glucose and elevated blood pressure components gave the strongest increase in SAF. Subjects with MetS having the impaired fasting glucose component had a 0.12 AU higher SAF compared to subjects without this particular component. A similar association was observed for individuals with MetS having the elevated blood pressure who had a 0.11 AU higher SAF than those without elevated blood pressure. Multivariate analyses showed that after adjusting for several determinants of SAF, elevated blood pressure (0.05 AU) and low HDL cholesterol $(0.04 \mathrm{AU})$ were significantly associated with higher SAF. Impaired fasting glucose, elevated triglycerides and enlarged waist circumference were not significantly associated with SAF. Regarding the clinical and lifestyle factors, age, HbA1c, current smoking, packyears and a history of CVD were all significantly associated with higher SAF whereas a higher creatinine clearance was associated with lower SAF.

\section{Discussion}

In the present study, we have demonstrated that SAF levels were higher in both male and female participants with MetS compared to those without MetS. Furthermore, SAF was significantly and independently associated with the presence of MetS and some of its individual components, particularly elevated blood pressure, impaired fasting glucose and enlarged waist circumference.

One of the main findings of the present study was that we observed significantly higher SAF levels in subjects with MetS compared to individuals without MetS, which is in line with a study by Den Engelsen et al. [33]. These authors observed higher SAF levels in obese subjects with MetS compared to those without MetS. The latter group may be considered as "healthy obese", which is also reflected by their SAF level. Additional analyses on our data showed a similar pattern (data not shown). In our study, $45 \%$ of men and $51 \%$ of women with MetS were obese, as defined by a BMI above $30 \mathrm{~kg} / \mathrm{m}^{2}$. However, within the population with MetS, we did not observe a statistically significant difference in SAF between obese and non-obese individuals. Within the same population, subjects with an enlarged waist circumference had higher SAF than subjects without an enlarged waist circumference. These findings imply that not general obesity but an enlarged waist circumference, or visceral obesity has more impact on SAF within individuals with MetS.

Next, our results may not be compared directly to those from Monami et al. [34] who have also shown that SAF levels are elevated among diabetic individuals with MetS. Mean SAF was higher than in our study as their cohort primarily consisted of type 2 diabetic individuals with a mean diabetes duration of 12 years. Individuals with type 2 diabetes have in general higher SAF than subjects 
without diabetes [9]. Furthermore, subjects in their study were older and had a higher prevalence of CVD, both are associated with higher SAF $[11,14]$.

In addition to the observation of higher SAF levels in subjects with MetS, we also found that a higher number of individual MetS components coincides with even higher SAF Z-scores. A previous study has already shown that a higher number of MetS components was associated with higher serum AGEs levels [35]. Clinical studies have demonstrated that a higher number of MetS components is associated with both incident CVD and type 2 diabetes [36-38]. Klein et al. showed that individuals with one MetS components had 2.5\% risk of incident CVD in the next 5 years whereas subjects with four or more MetS components had an almost $15 \%$ risk. The 5-years risk for type 2 diabetes increased from $1.1 \%$ (one MetS component) to $17.9 \%$ ( $\geq$ four MetS components) [36]. An 11-year follow-up study demonstrated an almost linear relationship between the number of individual MetS components and the risk of coronary heart disease in subjects without a history of CVD or type 2 diabetes [38]. Therefore, we suggest that an increase in SAF may reflect an even higher risk of type 2 diabetes and CVD.

It has been reported that the prevalence of both MetS and its components differ between men and women [39]. In men, we observed that elevated blood pressure was the most prevalent MetS component. Moreover, we found that subjects in the highest SAF group had a higher prevalence of elevated blood pressure compared to individuals in the intermediate or lowest SAF group. A few studies have described the association between SAF and elevated blood pressure, but the results are contradictory. For example, in renal transplant recipients, systolic blood pressure was positively associated with SAF [40] whereas neither systolic nor diastolic blood pressure was related to SAF in a recent Japanese study among type 2 diabetic individuals [41]. A recent study by Botros et al. [42] showed that both systolic and diastolic blood pressure were significantly associated with SAF. They showed that individuals with elevated blood pressure had a higher odds for having a SAF level > median, compared to subjects without elevated blood pressure. Elevated blood pressure may well be a consequence of increased AGE accumulation. A recent study demonstrated that carotidfemoral pulse-wave velocity and central pulse pressure were independently associated with plasma AGEs [43]. Several AGEs are able to form crosslinks within collagen in the vascular wall, which may result in impaired vascular elasticity and increased arterial stiffness, causing blood pressure to rise $[44,45]$. Our data together with previous studies suggest that AGE accumulation may indeed be involved in the underlying pathophysiology of elevated blood pressure.
In contrast to men among we found elevated blood pressure to be the most prevalent component, we observed that enlarged waist circumference was the most prevalent MetS component among women. Individuals with high SAF levels had a higher presence of enlarged waist circumference compared to subjects with intermediate or low SAF levels. However, in the multivariable analyses, enlarged waist circumference was not significantly associated with SAF. The correlation between waist circumference or BMI and higher SAF levels has been demonstrated among subjects with type 2 diabetes [34]. Recently, it has been shown that SAF levels were elevated among individuals with central obesity compared to lean subjects [33]. Interestingly, Angoorani et al. [46] have demonstrated that dietary consumption of AGEs is associated with MetS, and in particular abdominal obesity. Furthermore, it was observed that an increased consumption of food AGEs was associated with an even higher risk of (abdominal) obesity. They reported that individuals with a high AGEs consumption had a higher fat intake, and indeed it is known that fat contains a significant amount of dietary AGEs per gram of weight [47]. Another possible mechanism that has been reported to increase AGEs accumulation in obese individuals is oxidative stress $[48,49]$. Autoxidation of lipoproteins result in the formation of advanced lipoxidation end products formation (ALEs) such as carboxymethyllysine (CML) [1].

Next, we have shown that higher SAF is significantly associated with an increased presence of impaired fasting glucose. After adjusting for HbA1c, impaired fasting glucose was not associated with SAF probably as a consequence of high collinearity. A previous study already demonstrated that among subjects with central obesity, fasting glucose levels were significantly associated with higher SAF in univariate regression analyses but not after adjusting for covariables [33]. Another recent study reported no significant difference in plasma AGEs between women with normal fasting glucose and impaired fasting glucose [50]. As we included in our study subjects without diabetes only, and glucose levels were relatively low $(<6.9 \mathrm{mmol} / \mathrm{L})$, this may be the reason why fasting glucose was not associated with SAF. In individuals with diabetes, the formation of AGEs is accelerated particularly due to (chronic) hyperglycaemia [51]. Glucose plays an essential role in the formation of AGEs as protein amino groups and lipids are non-enzymatically glycated to form stable structures on long-lived tissues $[4,52]$. A second pathway which leads to the formation of AGEs is through autoxidation of glucose by reactive oxygen species and through formation of carbonyl compounds [1]. It has been shown that AGEs are involved in beta-cell injury, probably caused by inflammation and 
oxidative stress thought the AGE-RAGE interaction [53]. This may be prevented by consumption of a low-AGE diet, which has been suggested to improve insulin sensitivity [54, 55].

After adjusting for several determinants, having a low HDL cholesterol was significantly associated with higher SAF levels but elevated triglycerides was not. Among individuals with MetS, HDL was just above the limit in men and slightly decreased in women, while statin use was $13 \%$ in men and $10 \%$ in women. Additional analysis showed that statin users had significantly higher SAF Z scores than those not using statins, also after correcting for age. Triglycerides were slightly elevated in women, but higher in men. Around 1\% of individuals with MetS used triglycerides lowering medication. There was no significant difference in SAF Z scores between subject using triglycerides lowering medication and subjects not using this kind of medication. Limited data exist on the association between SAF and both HDL cholesterol and triglycerides. In subjects with type 2 diabetes, HDL cholesterol levels were negatively, and triglycerides were positively associated with SAF [14, 34]. Similar associations have been reported between serum AGEs levels and triglycerides and HDL cholesterol levels in diabetes [56]. In addition, higher consumption of AGE-rich foods was associated with hypertriglyceridemia [46]. HDL cholesterol has been reported to inhibit oxidative modification of LDL cholesterol [57]. A study in 200 type 2 diabetic subjects showed that higher anti-oxidative capacity of HDL was associated with lower SAF but not plasma HDL cholesterol levels itself [58]. Circulating AGEs may impair the capacity of HDL to protect against oxidation of LDL cholesterol which potentially increases oxidative stress. In turn this might accelerate the formation of AGEs [59] and plays a role in atherosclerosis [60].

The strength of this study is its large and well-characterized study population, including high quality data on anthropometric and clinical measurements. This resulted in a good statistical power and the ability to perform stratified analysis. Moreover, this is the largest study in subjects without diabetes and impaired renal failure showing the association between SAF and several cardiometabolic risk factors. A limitation of the study includes the cross-sectional design, which does not allow us to draw any conclusions about causality in the association between SAF levels and the risk of cardiometabolic diseases.

\section{Conclusion}

The present findings of elevated SAF levels in subjects with MetS, the positive association between the number of individual MetS components and higher SAF levels, as well as the observation that higher SAF levels are associated with higher prevalence of the individual components, provide further evidence that accumulation of AGEs may contribute to the pathophysiology of several cardiometabolic risk factors. Prospective studies are needed to demonstrate whether SAF measurement can be used as an additional non-invasive screening tool to detect individuals at high-risk for both CVD and incident type 2 diabetes.

\section{Abbreviations}

AGEs: advanced glycation end products; AU: arbitrary units; BMl: body mass index; CVD: cardiovascular disease; HDL: high density lipoprotein; MetS: metabolic syndrome; SAF: skin autofluorescence.

\section{Authors' contributions}

BHRW was the primary investigator. RPW and BHRW contributed to the study design. RPW performed the statistical analyses. RPW, BHRW, MMvdK, HLL, JVO, $R G$, SNS and ADP contributed to interpretation of the data and analyses. RPW drafted the manuscript. All authors read and approved the final manuscript.

\section{Author details}

1 Department of Endocrinology, University of Groningen, University Medical Center Groningen, HPC AA31, P.O. Box 30001, 9700 RB Groningen, The Netherlands. ${ }^{2}$ Program in Genetics and Genome Biology, Hospital for Sick Children, Toronto, ON M5G 0A4, Canada. ${ }^{3}$ Department of Internal Medicine, Medical Center Leeuwarden, 8934 AD Leeuwarden, The Netherlands.

\section{Acknowledgements}

The authors wish to acknowledge all participants of the LifeLines Cohort Study and everybody involved in the set-up and implementation of the study.

\section{Competing interests}

RG is founder and shareholder of DiagnOptics BV, Groningen, the Netherlands, manufacturer of the AGE Reader (http://www.diagnoptics.com) which has been used in the present study. All authors declare that they have no competing interest.

\section{Availability of data and materials}

The manuscript is based on data from the LifeLines Cohort Study. LifeLines adheres to standards for data availability. The data catalogue of LifeLines is publicly accessible on http://www.lifelines.net. All international researchers can apply for data at the LifeLines research office (LLscience@umcg.nl). The LifeLines system allows access for reproducibility of the study results.

\section{Ethics approval and consent to participate}

The study was approved by the Medical Ethical Committee of the University Medical Center Groningen. Informed consent was obtained from all individual participants included in the Lifelines study.

\section{Funding}

Lifelines has been funded by a number of public sources, notably the Dutch Government, The Netherlands Organization of Scientific Research NOW [Grant 175.010.2007.006], the Northern Netherlands Collaboration of Provinces (SNN), the European fund for regional development, Dutch Ministry of Economy Affairs, Pieken in de Delta, Provinces of Groningen and Drenthe, the Target project, BBMRI-NL, the University of Groningen, and the University Medical Center Groningen, The Netherlands. This work was supported by the National Consortium for Healthy Ageing, and funds from the European Union's Seventh Framework program (FP7/2007-2013) through the BioSHaRE-EU (Biobank Standardisation and Harmonisation for Research Excellence in the European Union) project, grant agreement 261433. LifeLines (BRIF4568) is engaged in a Bioresource research impact factor (BRIF) policy pilot study, details of which can be found at: https://www.bioshare.eu/content/bioresource-impact-factor.

\section{Prior presentations}

Parts of this study were presented in abstract form at the European Congress of Endocrinology (ECE), May 2016, Munich (Germany). 


\section{Publisher's Note}

Springer Nature remains neutral with regard to jurisdictional claims in published maps and institutional affiliations.

Received: 13 January 2017 Accepted: 23 May 2017

Published online: 30 May 2017

\section{References}

1. Baynes JW, Thorpe SR. Glycoxidation and lipoxidation in atherogenesis. Free Radic Biol Med. 2000:28(12):1708-16.

2. Monnier VM. Nonenzymatic glycosylation, the maillard reaction and the aging process. J Gerontol. 1990;45(4):B105-11.

3. Dunn JA, McCance DR, Thorpe SR, Lyons TJ, Baynes JW. Age-dependent accumulation of N. epsilon.-(carboxymethyl)lysine and N. epsilon.(carboxymethyl)hydroxylysine in human skin collagen. Biochemistry. 1991;30(5):1205-10

4. Dyer DG, Dunn JA, Thorpe SR, Bailie KE, Lyons TJ, McCance DR, et al. Accumulation of maillard reaction products in skin collagen in diabetes and aging. J Clin Investig. 1993;91(6):2463-9.

5. Noordzij MJ, Lefrandt JD, Smit AJ. Advanced glycation end products in renal failure: an overview. J Ren Care. 2008;34(4):207-12.

6. Brownlee M. Lilly lecture 1993. Glycation and diabetic complications. Diabetes. 1994:43(6):836-41.

7. Goldberg T, Cai W, Peppa M, Dardaine V, Baliga BS, Uribarri J, et al. Advanced glycoxidation end products in commonly consumed foods. J Am Diet Assoc. 2004;104(8):1287-91.

8. Cerami C, Founds H, Nicholl I, Mitsuhashi T, Giordano D, Vanpatten S, et al. Tobacco smoke is a source of toxic reactive glycation products. Proc Natl Acad Sci USA. 1997;94(25):13915-20.

9. Meerwaldt R, Graaff R, Oomen PH, Links TP, Jager JJ, Alderson NL, et al. Simple non-invasive assessment of advanced glycation endproduct accumulation. Diabetologia. 2004;47(7):1324-30.

10. van Waateringe RP, Slagter SN, van der Klauw MM, van Vliet-Ostaptchouk $J V$, Graaff R, Paterson AD, et al. Lifestyle and clinical determinants of skin autofluorescence in a population-based cohort study. Eur J Clin Investig. 2016;46(5):481-90.

11. Koetsier M, Lutgers HL, de Jonge C, Links TP, Smit AJ, Graaff R. Reference values of skin autofluorescence. Diabetes Technol Ther. 2010;12(5):399-403.

12. Meerwaldt R, Links T, Graaff R, Thorpe SR, Baynes JW, Hartog J, et al. Simple noninvasive measurement of skin autofluorescence. Ann N Y Acad Sci. 2005;1043:290-8.

13. van der Heyden JC, Birnie E, Mul D, Bovenberg S, Veeze HJ, Aanstoot HJ. Increased skin autofluorescence of children and adolescents with type 1 diabetes despite a well-controlled $\mathrm{HbA} 1 \mathrm{c}$ : results from a cohort study. BMC Endocr Disord. 2016;16(1):49.

14. Lutgers HL, Graaff R, Links TP, Ubink-Veltmaat LJ, Bilo HJ, Gans RO, et al. Skin autofluorescence as a noninvasive marker of vascular damage in patients with type 2 diabetes. Diabetes Care. 2006;29(12):2654-9.

15. Meerwaldt R, Lutgers HL, Links TP, Graaff R, Baynes JW, Gans RO, et al. Skin autofluorescence is a strong predictor of cardiac mortality in diabetes. Diabetes Care. 2007;30(1):107-12.

16. Meerwaldt R, Hartog JW, Graaff R, Huisman RJ, Links TP, den Hollander NC, et al. Skin autofluorescence, a measure of cumulative metabolic stress and advanced glycation end products, predicts mortality in hemodialysis patients. J Am Soc Nephrol. 2005;16(12):3687-93.

17. Kimura H, Tanaka K, Kanno M, Watanabe K, Hayashi Y, Asahi K, et al. Skin autofluorescence predicts cardiovascular mortality in patients on chronic hemodialysis. Ther Apher Dial. 2014;18(5):461-7.

18. Velayoudom-Cephise FL, Rajaobelina K, Helmer C, Nov S, Pupier E, Blanco $L$, et al. Skin autofluorescence predicts cardio-renal outcome in type 1 diabetes: a longitudinal study. Cardiovasc Diabetol. 2016;15(1):127.

19. Mulder DJ, van Haelst PL, Gross S, de Leeuw K, Biizet J, Graaff R, et al. Skin autofluorescence is elevated in patients with stable coronary artery disease and is associated with serum levels of neopterin and the soluble receptor for advanced glycation end products. Atherosclerosis. 2008;197(1):217-23.
20. de Vos LC, Noordzij MJ, Mulder DJ, Smit AJ, Lutgers HL, Dullaart RP, et al. Skin autofluorescence as a measure of advanced glycation end products deposition is elevated in peripheral artery disease. Arterioscler Thromb Vasc Biol. 2013;33(1):131-8.

21. den Dekker MA, Zwiers M, van den Heuvel ER, de Vos LC, Smit AJ, Zeebregts $C J$, et al. Skin autofluorescence, a non-invasive marker for AGE accumulation, is associated with the degree of atherosclerosis. PLOS ONE. 2013;8(12):e83084.

22. Grundy SM, Cleeman JI, Daniels SR, Donato KA, Eckel RH, Franklin BA, et al. Diagnosis and management of the metabolic syndrome: an american heart association/national heart, lung, and blood institute scientific statement. Circulation. 2005;112(17):2735-52.

23. Eckel RH, Grundy SM, Zimmet PZ. The metabolic syndrome. Lancet. 2005;365(9468):1415-28.

24. van Vliet-Ostaptchouk JV, Nuotio ML, Slagter SN, Doiron D, Fischer K, Foco $\mathrm{L}$, et al. The prevalence of metabolic syndrome and metabolically healthy obesity in Europe: a collaborative analysis of ten large cohort studies. BMC Endocr Disord. 2014;14:9.

25. Cameron AJ, Shaw JE, Zimmet PZ. The metabolic syndrome: Prevalence in worldwide populations. Endocrinol Metab Clin N Am. 2004;33(2):351-75.

26. Yang L, Colditz GA. Prevalence of overweight and obesity in the united states, 2007-2012. JAMA Intern Med. 2015;175(8):1412-3.

27. de Courten B, de Courten MP, Soldatos G, Dougherty SL, Straznicky N, Schlaich $M$, et al. Diet low in advanced glycation end products increases insulin sensitivity in healthy overweight individuals: a double-blind, randomized, crossover trial. Am J Clin Nutr. 2016;103(6):1426-33.

28. Ottum MS, Mistry AM. Advanced glycation end-products: modifiable environmental factors profoundly mediate insulin resistance. J Clin Biochem Nutr. 2015;57(1):1-12.

29. Stolk RP, Rosmalen JG, Postma DS, de Boer RA, Navis G, Slaets JP, et al. Universal risk factors for multifactorial diseases: LifeLines: A three-generation population-based study. Eur J Epidemiol. 2008;23(1):67-74.

30. Scholtens S, Smidt N, Swertz MA, Bakker SJ, Dotinga A, Vonk JM, et al. Cohort profile: LifeLines, a three-generation cohort study and biobank. Int J Epidemiol. 2015;44(4):1172-80.

31. Levey AS, Stevens LA, Schmid CH, Zhang YL, Castro AF, Feldman HI, et al. A new equation to estimate glomerular filtration rate. Ann Intern Med. 2009;150(9):604-12.

32. Hildrum B, Mykletun A, Hole T, Midthjell K, Dahl AA. Age-specific prevalence of the metabolic syndrome defined by the international diabetes federation and the national cholesterol education program: the norwegian HUNT 2 study. BMC Public Health. 2007;7:220.

33. den Engelsen C, van den Donk M, Gorter KJ, Salome PL, Rutten GE. Advanced glycation end products measured by skin autofluorescence in a population with central obesity. Dermatoendocrinology. 2012;4(1):33-8.

34. Monami M, Lamanna C, Gori F, Bartalucci F, Marchionni N, Mannucci E. Skin autofluorescence in type 2 diabetes: beyond blood glucose. Diabetes Res Clin Pract. 2008;79(1):56-60.

35. Uribarri J, Cai W, Woodward M, Tripp E, Goldberg L, Pyzik R, et al. Elevated serum advanced glycation endproducts in obese indicate risk for the metabolic syndrome: A link between healthy and unhealthy obesity?. J Clin Endocrinol Metab. 2015; jc20143925.

36. Klein BE, Klein R, Lee KE. Components of the metabolic syndrome and risk of cardiovascular disease and diabetes in beaver dam. Diabetes Care. 2002;25(10):1790-4.

37. Marott SC, Nordestgaard BG, Tybjaerg-Hansen A, Benn M. Components of the metabolic syndrome and risk of type 2 diabetes. J Clin Endocrinol Metab. 2016; jc20153777.

38. MCNeill AM, Rosamond WD, Girman CJ, Golden SH, Schmidt MI, East HE, et al. The metabolic syndrome and 11-year risk of incident cardiovascular disease in the atherosclerosis risk in communities study. Diabetes Care. 2005;28(2):385-90.

39. Kuk JL, Ardern Cl. Age and sex differences in the clustering of metabolic syndrome factors: association with mortality risk. Diabetes Care. 2010;33(11):2457-61.

40. Hartog JW, de Vries AP, Bakker SJ, Graaff R, van Son WJ, van der Heide JJ, et al. Risk factors for chronic transplant dysfunction and cardiovascular disease are related to accumulation of advanced glycation end-products in renal transplant recipients. Nephrol Dial Transplant. 2006;21(8):2263-9. 
41. Tanaka K, Tani Y, Asai J, Nemoto F, Kusano Y, Suzuki H, et al. Skin autofluorescence is associated with severity of vascular complications in japanese patients with type 2 diabetes. Diabet Med. 2012;29(4):492-500.

42. Botros N, Sluik D, van Waateringe RP, de Vries JH, Geelen A, Feskens EJ. Advanced glycation end-products (AGEs) and associations with cardiometabolic, lifestyle and dietary factors in a general population: the NQplus study. Diabetes Metab Res Rev. 2017;17:259.

43. van Eupen MG, Schram MT, van Sloten TT, Scheijen J, Sep SJ, van der Kallen CJ, et al. Skin autofluorescence and pentosidine are associated with aortic stiffening: the maastricht study. Hypertension. 2016;68(4):956-63.

44. Goldin A, Beckman JA, Schmidt AM, Creager MA. Advanced glycation end products: sparking the development of diabetic vascular injury. Circulation. 2006;114(6):597-605.

45. Aronson D. Cross-linking of glycated collagen in the pathogenesis of arterial and myocardial stiffening of aging and diabetes. J Hypertens. 2003;21(1):3-12.

46. Angoorani P, Ejtahed HS, Mirmiran P, Mirzaei S, Azizi F. Dietary consumption of advanced glycation end products and risk of metabolic syndrome. Int J Food Sci Nutr. 2016;67(2):170-6.

47. Uribarri J, Woodruff S, Goodman S, Cai W, Chen X, Pyzik R, et al. Advanced glycation end products in foods and a practical guide to their reduction in the diet. J Am Diet Assoc. 2010;110(6):911-916.e12.

48. Furukawa S, Fujita T, Shimabukuro M, Iwaki M, Yamada Y, Nakajima Y, et al. Increased oxidative stress in obesity and its impact on metabolic syndrome. J Clin Investig. 2004;114(12):1752-61.

49. Gaens KH, Stehouwer CD, Schalkwijk CG. Advanced glycation endproducts and its receptor for advanced glycation endproducts in obesity. Curr Opin Lipidol. 2013;24(1):4-11.

50. Teichert T, Hellwig A, Pessler A, Hellwig M, Vossoughi M, Sugiri D, et al. Association between advanced glycation end products and impaired fasting glucose: results from the SALIA study. PLOS ONE. 2015;10(5):e0128293.

51. Brownlee M, Cerami A, Vlassara H. Advanced glycosylation end products in tissue and the biochemical basis of diabetic complications. N Engl J Med. 1988;318(20):1315-21.

52. Brownlee M. Advanced protein glycosylation in diabetes and aging. Annu Rev Med. 1995;46:223-34.

53. Vlassara HSG. The role of advanced glycation end-products in the etiology of insulin resistance and diabetes. US Endocrinol. 2010;6(6):14-9.

54. Mark AB, Poulsen MW, Andersen S, Andersen JM, Bak MJ, Ritz C, et al. Consumption of a diet low in advanced glycation end products for 4 weeks improves insulin sensitivity in overweight women. Diabetes Care. 2014;37(1):88-95.

55. Uribarri J, Cai W, Ramdas M, Goodman S, Pyzik R, Chen X, et al. Restriction of advanced glycation end products improves insulin resistance in human type 2 diabetes: potential role of AGER1 and SIRT1. Diabetes Care. 2011;34(7):1610-6.

56. Chang JB, Chu NF, Syu JT, Hsieh AT, Hung YR. Advanced glycation end products (AGEs) in relation to atherosclerotic lipid profiles in middle-aged and elderly diabetic patients. Lipids Health Dis. 2011;10:228.

57. Soran H, Schofield JD, Liu Y, Durrington PN. How HDL protects LDL against atherogenic modification: paraoxonase 1 and other dramatis personae. Curr Opin Lipidol. 2015;26(4):247-56.

58. Mulder DJ, de Boer JF, Graaff R, de Vries R, Annema W, Lefrandt JD, et al. Skin autofluorescence is inversely related to $\mathrm{HDL}$ anti-oxidative capacity in type 2 diabetes mellitus. Atherosclerosis. 2011;218(1):102-6.

59. Zhou H, Tan KC, Shiu SW, Wong Y. Increased serum advanced glycation end products are associated with impairment in HDL antioxidative capacity in diabetic nephropathy. Nephrol Dial Transplant. 2008;23(3):927-33.

60. Stocker R, Keaney JF Jr. Role of oxidative modifications in atherosclerosis. Physiol Rev. 2004;84(4):1381-478.

\section{Submit your next manuscript to BioMed Central and we will help you at every step:}

- We accept pre-submission inquiries

- Our selector tool helps you to find the most relevant journal

- We provide round the clock customer support

- Convenient online submission

- Thorough peer review

- Inclusion in PubMed and all major indexing services

- Maximum visibility for your research

Submit your manuscript at www.biomedcentral.com/submit
() Biomed Central 